\title{
Control Yourself! Examining the Dimensions of Eudaimonic Psychological Well-Being as Related to Locus of Control Using Structural Equation Modeling
}

\author{
Tionna M. Hough*, Heather A. Labansat, T. Forest Moore, Rene Wallace, Kristina Higgins \\ Psychological Sciences, Tarleton State University
}

${ }^{*}$ Corresponding author email: tionna.hough@go.tarleton.edu

Received: 14 June 2021 / Revised: 19 July 2021 / Accepted: 29 July 2021 / Published: 21 August 2021

\begin{abstract}
Current literature on the relationship between locus of control (LOC) and psychological well-being (PWB) consistently demonstrates that individuals with an internal LOC generally report experiencing greater psychological well-being than externally-oriented individuals. However, there is minimal depth of understanding regarding the specific dynamics of this well-established relationship. The aims of the present quantitative study were (a) to replicate and provide support for the existing knowledge on the relationship between these two factors and (b) to use a structural equation model (SEM) to further explore the relationship between LOC and the six dimensions in Ryff's model of eudaimonic PWB, which are combined to assess one's psychological welfare. Using cross-sectional survey methodology, 267 adult participants were recruited through convenience and snowball sampling to anonymously complete a series of questionnaires online. A Pearson $r$ bivariate correlation analysis examining the relationship between PWB and LOC revealed a significant negative correlation between the two constructs $(r=-.280, p=.001)$. This finding replicates previous research, where individuals with an internal LOC reported experiencing significantly greater PWB, while individuals with an external LOC reported significantly less PWB. In order to further examine how the six factors of PWB (selfacceptance, positive relationships, autonomy, environmental mastery, purpose in life, and personal growth) relate to LOC, a SEM was performed. Although all six dimensions of PWB show significant negative correlations with LOC, environmental mastery, self-acceptance, and purpose in life were the most impactful on the relationship between these two constructs, as they were shown to have higher significance in the SEM. Considering the SEM suggests that environmental mastery, self-acceptance, and purpose in life are the most weighted factors of PWB's correlation to LOC, possible interventions on these factors in a clinical or applied setting may see improvement in the relationship between PWB and LOC.
\end{abstract}

Keywords: locus of control, psychological well-being, structural equation model

\section{Introduction}

Historically, research in psychology focused predominantly on the occurrence of dysfunction, its causes, and its antidotes (Linley et al., 2006). However, the continued rise of the positive psychology movement has brought with it a substantial shift in focus: Rather than emphasizing psychological dysfunction, researchers have begun to examine individual strengths and their contributions to psychological well-being, which is associated with advantageous physical, social, and psychological health outcomes (Carmeli et al., 2009; Khumalo \& Plattner, 2021; Kubzansky et al., 2018; Linley et al., 2006). Given its close association with these positive life outcomes, many researchers seek to isolate what factors or traits may facilitate the attainment of psychological well-being (Akhtar \& Kroener-Herwig, 2019; Kardas et al., 2019; Poudel et al., 2020; Stevenson et al., 2019; Xia \& Ma, 2020). One trait that appears to reliably predict an individual's level of psychological well-being is their locus of control (Baluku et al., 2021; Di 
Pentima et al., 2019; Enwere \& Mbakwe, 2021; Skomorovsky \& Wan, 2019). Based on these considerations, the primary purpose of this study was to replicate previous findings that internal loci of control predict higher levels of psychological well-being. Additionally, we sought to expand upon the understanding of this relationship through use of structural equation modeling to discern how heavily each factor of eudaimonic psychological well-being influences overall eudaimonic psychological well-being and, subsequently, is associated with locus of control.

\subsection{Locus of Control}

An individual's locus of control refers to the degree to which they believe they are able to maintain primary influence over experiences and outcomes in their life (Rotter, 1954 \& 1966). Rotter provides an operationalized definition of locus of control, which depicts this construct as a dimensional trait with two bipolar extremes: Internal locus of control and external locus of control. Individuals who are oriented toward an internal locus of control generally believe they can effectively influence and control various aspects of their lives, such as their social environment, life circumstances, and the outcome of their behaviors. Conversely, individuals who are oriented toward an external locus of control tend to doubt these abilities, instead feeling as though they possess minimal or no influence over their situation, and that it is the environment that controls them and determines the consequences of their behaviors.

While Rotter (1966) is certain to note that neither loci of control is inherently superior to the other, several studies indicate that a general orientation toward an internal locus of control is more frequently associated with benefits in a variety of areas, such as physical health, interpersonal relationships, academic achievement, and job performance (Hopkins et al., 2020; Levy \& Gumpel, 2020; Kesavayuth et al., 2020; Strong \& Gore, 2020). Given the evident benefits of orientation toward an internal locus of control, researchers have worked extensively to confirm the association between locus of control and various measures of psychological well-being (Baluku et al., 2021; Di Pentima et al., 2019; Enwere \& Mbakwe, 2021; Skomorovsky \& Wan, 2019). With a public interest in mental health awareness and an emphasis on positive psychology today, psychological well-being is a continuously growing area of research.

\subsection{Psychological Well-being}

The earliest conceptions of well-being began to emerge millennia ago through the birth of philosophy and the musings of such notable figures as Aristotle (Aristotle et al., 2011). Throughout time, countless definitions of well-being have been proposed, but each model or theory generally reflects one of two fundamental philosophies: Hedonism or eudaimonism. The hedonic perspective of well-being emphasizes such pursuits as comfortability, general satisfaction, and achieving pleasure. Conversely, the eudaimonic perspective of well-being is characterized by self-development, positive contribution to society, and a general feeling of having purpose in life. Through intensive literature review and her own research findings, Ryff (1989) expanded on this concept and developed a model of eudaimonic psychological well-being that emphasizes personal development and self-realization. Ryff operationally defines eudaimonic psychological well-being to include six dimensions: Self-acceptance, positive relations with others, autonomy, environmental mastery, purpose in life, and personal growth.

The first dimension of eudaimonic psychological well-being is self-acceptance, which is characterized by positive self-perception, neutral acceptance of one's beneficial and detrimental qualities, and a general sense of peace when reflecting on one's past life (Ryff, 1989). Positive relations with others, the second dimension of eudaimonic psychological well-being, entails maintaining interpersonal relationships that are generally trusting and affectionate. The third dimension of eudaimonic psychological well-being, autonomy, includes such qualities as self-sufficiency, individuality, and general orientation toward an internal locus of evaluation. The fourth dimension of eudaimonic psychological well-being is environmental mastery, which reflects how well an individual is able to navigate and impact their environment. Purpose in life is the fifth dimension of eudaimonic psychological well-being, and it includes the belief that the reason for one's existence is not aimless and meaningless, but rather that their life has 
Hough et al., Adv. J Social Sci.; Vol. 8, Issue 1, pp: 246-255, 2021

greater and deeper meaning. The sixth and final dimension of eudaimonic psychological well-being is personal growth, which entails ceaseless self-expansion and evolution, throughout which individuals' journey toward their ultimate potential. The current research has established an overall relationship between psychological well-being and locus of control but has not examined how these six dimensions individually influence locus of control.

\subsection{Relationship Between Psychological Well-being \& Locus of Control}

Research on psychological well-being consistently demonstrates its association with a variety of benefits, such as improved physical health, positive interpersonal relationships, and healthy intrapersonal functioning. For instance, previous studies indicate that psychological well-being is correlated with healthier immune functioning, quicker recovery from illness, and higher life expectancy (Diener \& Biswas-Diener, 2008; Pressman \& Cohen, 2005). Individuals with greater psychological well-being also tend to engage in more prosocial behavior, feel greater satisfaction in interpersonal relationships, and experience increased positive affect and mental health (Diener \& Seligman, 2004; King, 2008; Lyubomirsky et al., 2005; Veenhoven, 2008).

Several studies exploring the relationship between locus of control and psychological well-being indicate that an individual's locus of control may influence or predict their level of psychological well-being (Baluku et al., 2021; Di Pentima et al., 2019; Enwere \& Mbakwe, 2021; Skomorovsky \& Wan, 2019; Sona et al., 2020). Specifically, the findings of these studies suggest that a general orientation toward an internal locus of control is associated with higher levels of psychological well-being. In a sample of secondary school adolescents, students with an internal locus of control reported greater psychological well-being than did their externally-oriented peers (Enwere \& Mbakwe, 2021). Further research on locus of control in adolescents found a significant positive relationship between internal locus of control, happiness, and gratitude (Sona et al., 2020). Among military members with and without dependent family members, having an external locus of control predicted greater psychological distress and less psychological well-being when encountering financial strain (Skomorovsky \& Wan, 2019). Similarly, in a sample composed of individuals with varying employment statuses, Baluku and colleagues (2021) determined that an external locus of control was negatively associated with eudaimonic psychological well-being.

\subsection{The Present Study}

The purpose of the present study was two-fold, with aims to both replicate and expand upon previous findings consistently reported throughout the literature. Specifically, we sought first to provide further support for the existent knowledge that internal loci of control predict higher levels of psychological well-being. In our review of the literature, we observed that while previous studies reported on the general relationship between these two factors, they did not report further exploration into each dimension of eudaimonic well-being depicted in Ryff's (1989) model. As such, we used structural equation modeling to examine how strongly each factor of eudaimonic psychological well-being influences overall eudaimonic psychological well-being and, subsequently, relates to locus of control.

\section{Methodology}

\subsection{Participants}

The sample consisted of 267 participants recruited through convenience sampling using social media (Facebook, Twitter, and Instagram) and flyers. Inclusion criteria required all participants to be at least 18 years old to provide consent, and participant ages ranged from 18 to $80+$. Any participants that did not complete the entire questionnaire were excluded from data analyses. Participants were recruited under the general understanding that they would complete a survey of questions regarding psychological well-being, but they were not privy to the specific aims of the study, and all measures were de-identified within the survey. For quality control, Qualtrics includes a built-in security system that ensures no duplicate IP addresses were used and that no bots or non-human participants completed the survey. The sample 
consisted of 184 females, 76 males, and 7 individuals who preferred not to disclose their gender. Participants did not receive compensation for completing the study.

\subsection{Measures}

\subsubsection{Locus of Control}

The participants' loci of control were evaluated using the Internal-External Locus of Control Scale (Rotter, 1966). The Internal-External Locus of Control Scale is a two-alternative forced choice measure, which consists of 29 pairs of statements that examine an individual's orientation toward an external locus of control (see Figure 1). This measure demonstrates good test-retest reliability, with reliability coefficients ranging from .49-.83 over one to two months, and .64 in a sample tested across two years (Lange \& Tiggemann, 1981). Interscale correlation analyses between Rotter's Internal-External Locus of Control Scale and the locus of control measures created by Reid and Ware (1974, as cited by Goodman \& Waters, 1987), Nowicki and Duke (1974, as cited by Goodman \& Waters, 1987), and Levenson (1974, as cited by Goodman \& Waters, 1987) yielded Cronbach's $\alpha$ scores of .55, .46, and .45 respectively, which indicates this measure's convergent validity (Goodman \& Waters, 1987). Sample statement pairs from this measure include, "a. Many of the unhappy things in people's lives are partly due to bad luck; or b. People's misfortunes result from the mistakes they make," and "a. I have often found that what is going to happen will happen; or b. Trusting to fate has never turned out as well for me as making a decision to take a definite course of action." For each item on the measure, participants indicated which of the statements they agreed most with.

\section{Locus of Control}

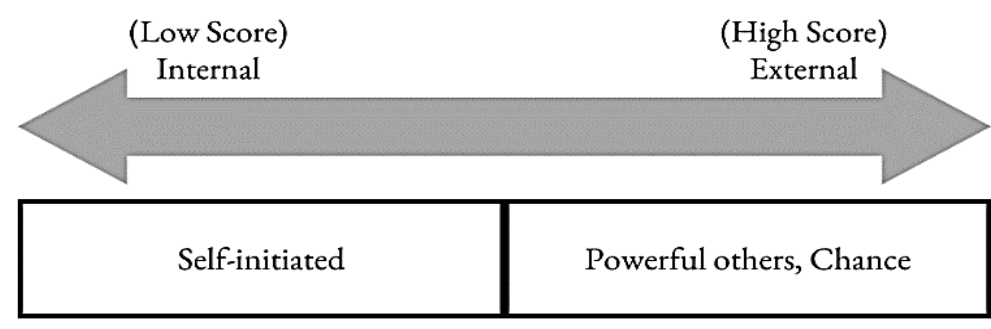

Figure 1: Locus of Control construct.

\subsubsection{Psychological Well-being}

Participants' eudaimonic psychological well-being was evaluated using Ryff's Scales of Psychological Well-being (Ryff, 1989). Ryffs Scales of Psychological Well-being consists of 42 questions across six subscales that measure the following factors of eudaimonic psychological well-being: Selfacceptance, Positive Relations with Others, Autonomy, Environmental Mastery, Purpose in Life, and Personal Growth. The reliability of this measure is evident through its internal consistency, with each subscale yielding high Cronbach's $\alpha$ scores $(\alpha=.70-.80$; Choi $\&$ Kim, 2011). Scores on the subscales of Ryff's Scales of Psychological Well-being converge strongly with similar components of related measures, such as the Life Satisfaction Index (Neugarten et al., 1961, as cited in Ryff, 1989) the Affect Balance Scale (Bradburn, 1969, as cited in Ryff, 1989), and Rosenberg's Self-Esteem Scale (1965, as cited in Ryff, 1989), with coefficients ranging from .25 to .73 (Ryff, 1989), which demonstrates its convergent validity. Sample items include, "I am not afraid to voice my opinions, even when they are in opposition to the opinions of most people," and "When I think about it, I haven't really improved much as a person over the years." Participants rated the 42 items using a Likert scale ranging from 1 (Strongly Agree) to 7 (Strongly Disagree).

\subsection{Procedure}

Participants followed a link to Qualtrics (Qualtrics, 2020), where they first read the informed consent for the study. In the informed consent, participants read that their participation was voluntary, and that they could withdraw from the study at any time. Upon providing consent, participants completed a 
Hough et al., Adv. J Social Sci.; Vol. 8, Issue 1, pp: 246-255, 2021

series of self-report measures consisting of a demographic's questionnaire, the Locus of Control Scale (Rotter, 1966), and Ryff's Scales of Psychological Well-being (Ryff, 1989). Once they completed the survey, participants read the debriefing form, where they learned the purpose of the study, were thanked for their participation, and were dismissed.

\subsection{Data Analysis}

To replicate previous findings, a Pearson $r$ bivariate correlation was conducted to determine an overall relationship between psychological well-being and locus of control. Once the relationship between the overall score for psychological well-being and locus of control was determined, a confirmatory factor analysis was performed on the six dimensions of psychological well-being to determine how each impacts the latent variable. Then, structural equation modeling was used to determine how each of the dimensions of psychological well-being contributed to overall psychological well-being and how this influences locus of control.

\section{Results}

The first goal of this study intended to replicate previous findings from the literature that show an overall relationship between locus of control and psychological well-being; thus, a Pearson $r$ bivariate correlation was conducted to explore this relationship. The results indicated a significant negative correlation between locus of control and overall psychological well-being $r=-0.280, p<.001$. Further analyses were run to determine the relationship between locus of control and each of the six factors of psychological well-being. The results of the bivariate correlations indicated a statistically significant negative relationship between locus of control and each of the six factors of psychological well-being, as shown in Table 1.

Table 1: Locus of Control and Psychological Well-being.

\begin{tabular}{|c|l|l|l|l|l|l|l|l|}
\hline \multirow{4}{*}{$\begin{array}{c}\text { Locus } \\
\text { of } \\
\text { Control }\end{array}$} & $\begin{array}{l}\text { Psychological } \\
\text { Well-Being }\end{array}$ & \begin{tabular}{l} 
Autonomy \\
\cline { 2 - 8 }
\end{tabular} & $\begin{array}{l}\text { Environmental } \\
\text { Mastery }\end{array}$ & $\begin{array}{l}\text { Personal } \\
\text { Growth }\end{array}$ & $\begin{array}{l}\text { Positive } \\
\text { Relationships }\end{array}$ & $\begin{array}{l}\text { Purpose } \\
\text { In Life }\end{array}$ & $\begin{array}{l}\text { Self- } \\
\text { Acceptance }\end{array}$ \\
\cline { 2 - 8 } & $\begin{array}{l}\text { Correlation } \\
\text { Sig. (2- } \\
\text { tailed) }\end{array}$ & -.280 & -.198 & -.231 & -.134 & -.131 & -.231 & -.306 \\
\hline
\end{tabular}

Next, a confirmatory factor analysis was conducted with the six factors of psychological well-being to determine the influence it has on the overall latent construct. All six factors loaded highly (see Table 2), and model fit indices indicated that the six-factor model for psychological well-being was effective (comparative fit index $[\mathrm{CFI}]=0.91$, root mean square error of approximation $[\mathrm{RMSEA}]=0.126)$.

Table 2: Unstandardized and standardized parameter estimates for the confirmatory factor analysis.

\begin{tabular}{|l|l|l|l|}
\hline Parameter & Unstandardized Estimate & SE & Standardized Estimate \\
\hline Environmental Mastery -> PWB & 1.245 & 0.163 & $0.776^{* * *}$ \\
\hline Personal Growth -> PWB & 0.993 & 0.133 & $0.641^{* * *}$ \\
\hline Positive Relations -> PWB & 1.436 & 0.205 & $0.640^{* * *}$ \\
\hline Purpose in Life -> PWB & 1.455 & 0.197 & $0.720^{* * *}$ \\
\hline Self-Acceptance -> PWB & 2.219 & 0.287 & $0.878^{* * *}$ \\
\hline Autonomy -> PWB & $1.000^{\mathrm{a}}$ & -- & $0.482^{* * *}$ \\
\hline
\end{tabular}


Control Yourself! Examining the Dimensions of Eudaimonic Psychological Well-Being as Related to Locus of Control ...

Because each factor is individually related to psychological well-being, a Structural Equation Model was created to assess how the individual factors comprising psychological well-being contributed to the latent variable psychological well-being and subsequently were related to locus of control. All factors loaded highly (see Table 3), and model fit indices showed a strong fit $(\mathrm{CFI}=0.92$; RMSEA $=0.102)$.

Table 3: Unstandardized and standardized parameter estimates for the structural equation model.

\begin{tabular}{|l|l|l|l|}
\hline Parameter & Unstandardized Estimate & SE & Standardized Estimate \\
\hline Environmental Mastery -> PWB & $1.000^{\mathrm{a}}$ & -- & $0.772^{* * *}$ \\
\hline Personal Growth -> PWB & 0.756 & 0.073 & $0.643^{*}$ \\
\hline Positive Relations -> PWB & 1.144 & 0.112 & $0.632^{*}$ \\
\hline Purpose in Life -> PWB & 1.179 & 0.099 & $0.723^{* * *}$ \\
\hline Self-Acceptance -> PWB & 1.841 & 0.128 & $0.880^{* * *}$ \\
\hline Autonomy -> PWB & 0.814 & 0.106 & $0.487^{* *}$ \\
\hline PWB <-> Locus of Control & -0.324 & 0.067 & $-0.312^{* *}$ \\
\hline
\end{tabular}

${ }^{a}$ Parameter fixed to 1.00 , therefore no SE was present. ${ }^{*} p<.05,{ }^{* *} p<.01,{ }^{* * *} p<.001$

To further examine the relationship between the latent variable psychological well-being and locus of control scores, a structural equation model analysis was performed on the data from our 267 participants using AMOS (version 27) on the two Likert-scale questionnaires on psychological well-being (Ryff, 1989) and locus of control (Rotter, 1966). Standardized estimates for three of the factors loaded the highest: SelfAcceptance $(-.88, p<.001)$, Purpose in Life $(-.72, p<.001)$, and Environmental Mastery $(-.77, p<.001)$ (see Figure 2).

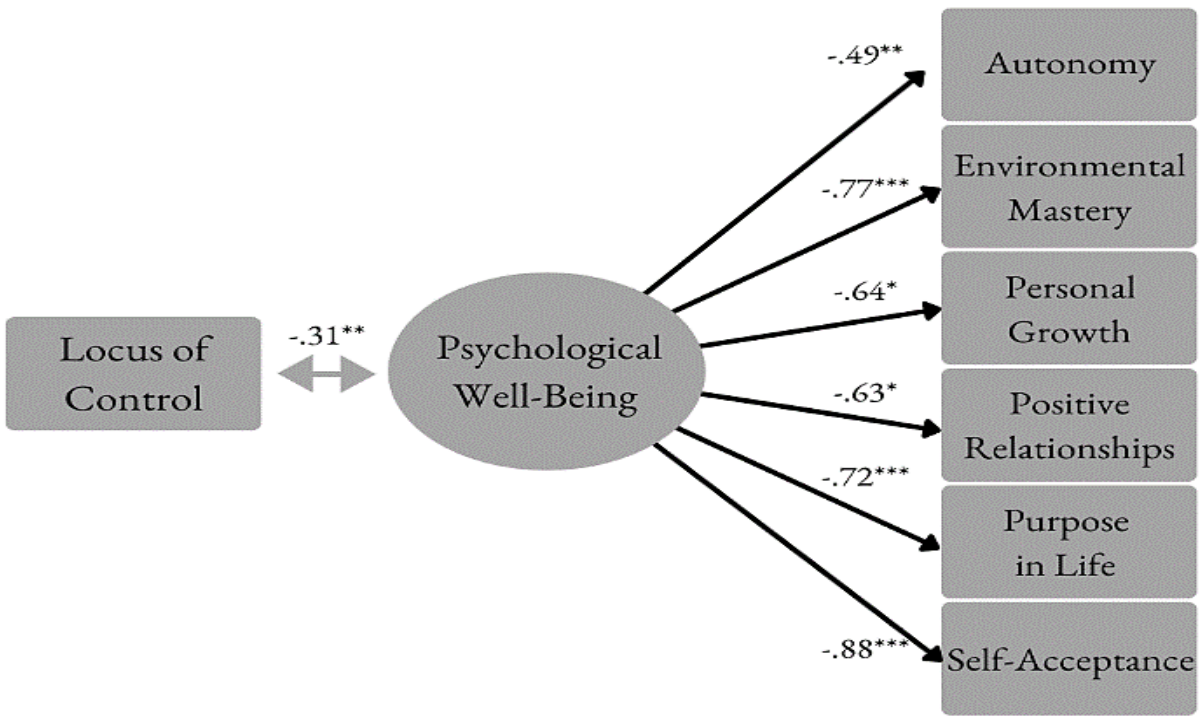

Figure 2: Structural Equation Model depicting relationship between Locus of Control and latent Psychological Well-Being.

\section{Discussion}

This study investigated how one's locus of control relates to their sense of eudaimonic psychological well-being and expanded upon the understanding of this relationship through structural 
equation modeling of the six factors of eudaimonic psychological well-being (self-acceptance, positive relationships, autonomy, environmental mastery, purpose in life, and personal growth) and their relationship with locus of control. We employed a Pearson $r$ bivariate correlation analysis to examine the relationship between locus of control and eudaimonic psychological well-being and found that individuals who are generally oriented toward an internal locus of control reported greater eudaimonic psychological well-being than did individuals with an external locus of control. Next, we conducted a confirmatory factor analysis with the six factors of psychological well-being, and we determined all six factors contribute highly to the overall construct. This finding replicates Ryff's original work that identified six distinct factors of eudaimonic psychological well-being.

We ran further Pearson $r$ bivariate correlational analyses to determine the relationship between locus of control and each of the six factors of eudaimonic psychological well-being, of which selfacceptance, purpose in life, and environmental mastery had the strongest associations with an internal locus of control. This finding lends support to the previous research regarding the general relationship between locus of control and psychological well-being. Finally, we expanded upon previously-held knowledge through structural equation modeling that depicted the relationship between locus of control and the latent variable eudaimonic psychological well-being. Of the six factors of eudaimonic psychological well-being, self-acceptance, purpose in life, and environmental mastery contributed most substantially to overall eudaimonic psychological well-being and, subsequently, have the greatest influence on its relationship to one's locus of control.

\subsection{Implications}

To the best of our knowledge, this is the first study to examine the underlying influence of each factor of eudaimonic psychological well-being on the relationship between overall eudaimonic psychological well-being and locus of control. Given the novelty of this finding, understanding the driving forces in the relationship between locus of control and psychological well-being has important implications for both research and practice. For instance, the belief that one has primary control over most aspects of their life and can effectively manage any problems that emerge (i.e., orientation toward an internal locus of control) is a key component of hardiness, a trait that protects against negative mental health outcomes, such as anxiety, depression, and somatization (Maddi \& Khoshaba, 1994; Nowack \& Niemirowski, 2021). As such, individuals with an internal locus of control appear more likely to exhibit hardiness and fewer negative mental health outcomes than individuals with an external locus of control. For clinicians working with individuals who experience anxiety, depression, and somatization, efforts to assess clients' locus of control and, if necessary, facilitate their reorientation toward a moderately internal locus of control may prove beneficial in moderating these symptoms.

This emphasis placed on reorienting one's locus of control may impart further benefits beyond reducing these manifestations of dysfunction. The findings of this study suggest the potential for clinicians and researchers to effectively enhance individuals' eudaimonic psychological well-being by way of facilitating their shift toward an internal locus of control. More specifically, the structural equation model suggests that of the components of eudaimonic psychological well-being, this positive change in locus of control will have the greatest impact on increasing self-acceptance, generating greater feelings of purpose in life, and improving environmental mastery. Inversely, the goal of improving eudaimonic psychological well-being as the focal point of treatment or research may indirectly influence locus of control through the shift toward a more advantageous internal orientation. Based on the results of this study, it appears that this effect is more likely to be observed under conditions that emphasize self-acceptance, purpose in life, and environmental mastery.

\subsection{Limitations \& Future Directions}

One limitation of this study is the demographic make-up of the participants in its sample. The sample for this study consisted disproportionately of female participants, which does not accurately reflect 
the gender composition of the overall population. Future studies should seek to recruit a more representative sample, which will in turn will increase the generalizability of the research findings. A further limitation of this study is the self-report nature of the data collected. It is unclear how accurately selfreported data reflects actual lived experience. The self-report of data presents the opportunity for participants to consciously or unconsciously manipulate their responses in a way that may make them appear more or less favorable than they truly are. Future studies may wish to utilize implicit measures, direct observation, longitudinal methods, or data reported by individuals closely associated with the research participants to eliminate the limitations associated with self-reported data or to assess potential discrepancies between self-reported data and data collected through other methods.

The findings of this study suggest the potential utility of training and interventions centered around shifting participants toward an internal locus of control as effective methods to enhance eudaimonic psychological well-being. Moreover, it appears training and interventions that emphasize the three components of eudaimonic psychological well-being that most directly influence locus of control (selfacceptance, purpose in life, and environmental mastery) may prove beneficial in efforts to re-orient individuals toward an internal locus of control. Based on these premises, future research directions should explore the development, implementation, and efficacy of such interventions.

While it is evident that a general orientation toward an internal locus of control is more advantageous to eudaimonic psychological well-being and other positive life outcomes than having an external locus of control (Hopkins et al., 2020; Levy \& Gumpel, 2020; Kesavayuth et al., 2020), researchers have cautioned against considering either loci of control as being inherently superior to the other (April et al., 2012; Rotter, 1964). It appears that holding an excessively internal locus of control may be just as detrimental to overall well-being as a general orientation toward an external locus of control, if not more (Periasamy \& Ashby, 2002; Walsh et al., 1997). However, it has yet to be determined at what point an internal locus of control reaches excess and becomes harmful rather than beneficial. As such, it is imperative for further research to explore these boundaries in order to optimize efforts in the reorientation process and minimize the potential for harm.

\section{Conclusion}

This study demonstrated that orientation toward an internal locus of control predicts higher levels of eudaimonic psychological well-being than an external orientation. This finding lends support to the previous research regarding the general relationship between locus of control and psychological well-being. Through novel, in-depth exploration of this relationship using structural equation modeling, we determined that of the six dimensions of psychological well-being, self-acceptance, purpose in life, and environmental mastery contributed most substantially to the overall relationship between eudaimonic psychological wellbeing and locus of control. The results of this study may have potential utility in clinical settings, where clinicians may find it beneficial to help clients shift toward an internal locus of control as a method to enhance psychological well-being. Additionally, these findings provide insight into which components of psychological well-being a positive shift in locus of control may have the greatest impact on (e.g., selfacceptance, purpose in life, and environmental mastery). Based on these premises, future research directions should explore the development, implementation, and efficacy of such interventions. Furthermore, while a balanced locus of control (i.e., a mix of internal and external qualities) is recommended over a purely internal-orientation, it has yet to be determined at what point an internal locus of control reaches excess and becomes harmful rather than beneficial. As such, it is imperative for further research to explore these boundaries and provide greater insight into how to improve locus of control while minimizing the risk for potential negative outcomes. 


\section{Declarations}

\subsection{Study Limitations}

1. One limitation of this study is the demographic make-up of the participants in its sample. The sample for this study consisted disproportionately of female participants, which does not accurately reflect the gender composition of the overall population.

2. A further limitation of this study is the self-report nature of the data collected. It is unclear how accurately self-reported data reflects actual lived experience. The self-report of data presents the opportunity for participants to consciously or unconsciously manipulate their responses in a way that may make them appear more or less favorable than they truly are.

\subsection{Informed Consent}

Informed consent was obtained before respondents were administered the questionnaire. Data was collected anonymously through a safe and secure data collection program with access limited to the research team.

\subsection{Competing Interests}

None of the authors listed on this paper had a conflict of interest with this project.

\subsection{Publisher's Note}

AIJR remains neutral with regard to jurisdictional claims in published maps and institutional affiliations.

\section{How to Cite this Article:}

Hough, T. M., Labansat, H. A., Moore, T. F., Wallace, R., \& Higgins, K. (2021). Control Yourself! Examining the Dimensions of Eudaimonic Psychological Well-Being as Related to Locus of Control Using Structural Equation Modeling. Advanced Journal of Social Science, 8(1), 246-255. https://doi.org/10.21467/ajss.8.1.246-255

\section{References}

Akhtar, M. \& Kroener-Herwig, B. (2019). Coping styles and socio-demographic variables as predictors of psychological well-being among international students belonging to different cultures. Current Psychology, 38, 618-626. https://doi.org/10.1007/s12144-017-9635-3

April, K. A., Dharani, B., \& Peters, K. (2012). Impact of locus of control expectancy on level of well-being. Review of European Studies, 4(2). https://doi.org/10.5539/res.v4n2p124

Aristotle. (2011). Aristotle's Nicomachean ethics. University of Chicago Press. (Original work published ca. 340 B.C.E./1994)

Baluku, M. M., Bantu, E., Namale, B., \& Otto, K. (2021). Maintaining high eudaimonic wellbeing despite ambiguity intolerance among three employment status groups: Examining the buffering effects of positive psychological attributes. International Journal of Applied Positive Psychology. https://doi.org/10.1007/s41042-021-00051-1

Carmeli, A., Yitzhak-Halevy, M., \& Weisberg, J. (2009). The relationship between emotional intelligence and psychological wellbeing. Journal of Managerial Psychology, 24(1), 66-78. https://www.emerald.com/insight/content/doi/10.1108/02683940910922546/full/html

Choi, N. G. \& Kim, J. (2011) The effect of time volunteering and charitable donations in later life on psychological wellbeing. Ageing and Society, 31(4), 590-610.

Di Pentima, L., Toni, A., Schneider, B. H., Tomás, J. M., Oliver, A., \& Attili, G. (2019). Locus of control as a mediator of the association between attachment and children's mental health. The Journal of Genetic Psychology, 180(6), 251-265. https://doi.org/10.1080/00221325.2019.1652557

Diener, E. \& Biswas-Diener, R. (2008) Happiness: Unlocking the mysteries of psychological wealth. Blackwell Publishing.

Diener, E. \& Seligman, M.E. (2004). Beyond money. Toward an economy of well-being. Psychological Science in the Public Interest, 5(1), 1-31. https://doi.org/10.1111/j.0963-7214.2004.00501001.x

Enwere, C. A. \& Mbakwe, U. F. (2021). Self esteem and locus of control as predictors of psychological wellbeing of senior secondary school adolescents in Anambra State. International Journal of Innovative Social \& Science Education Research, 9(2), 30-48. https://seahipaj.org/journals-ci/june-2021/IJISSER/full/IJISSER-J-4-2021.pdf

Goodman, S. H. \& Waters, L. K. (1987). Convergent validity of five locus of control scales. Educational and Psychological Measurement, 47, 743-747.

Hopkins, C., Ferrell, O. C., Ferrell, L., Hopkins, K., \& Merkle, A. C. (2020). Self-efficacy, locus of control and engagement as determinants of grades in a principles of marketing class. Marketing Education Review, 30(4), 236-251. https://doi.org/10.1080/10528008.2020.1837634

IBM Corp. Released 2020. IBM SPSS Statistics for Windows, Version 27.0. Armonk, NY: IBM Corp

Kardas, F., Cam, Z., Eskisu, M., \& Gelibolu, S. (2019). Gratitude, hope, optimism and life satisfaction as predictors of psychological wellbeing. Eurasian Journal of Educational Research, 19(82), 81-100. https://dergipark.org.tr/en/pub/ejer/issue/48089/608137 
Kesavayuth, D., Poyago-Theotoky, J., Tran, D. B., \& Zikos, V. (2020). Locus of control, health and healthcare utilization. Economic Modelling, 86, 227-238. https://doi.org/10.1016/j.econmod.2019.06.014

Khumalo, T. \& Plattner, I. E. (2019). The relationship between locus of control and depression: A cross-sectional survey with university students in Botswana. South African Journal of Psychiatry, 25. doi: 10.4102/sajpsychiatry.v25i0.1221

King, L. A. (2008). Interventions for enhancing subjective well-being: Can we make people happier and should we? In: M Eid, RJ Larsen, (eds.) The Science of Subjective Well-Being. Guilford Press.

Kubzansky, L. D., Huffman, J. C., Boehm, J. K., Hernandez, R., Kim, E. S., Koga, H. K., Feig, E. H., Lloyd-Jones, D. M., Seligman, M. E. P., \& Labarthe, D. R. (2018). Positive psychological well-being and cardiovascular disease. Journal of the American College of Cardiology, 72(12), 1382-1396. doi: 10.1016/j.jacc.2018.07.042.

Lange, R. V. \& Tiggemann, M. (1981). Dimensionality and reliability of the Rotter I-E Locus of Control Scale. Journal of Personality Assessment, 45(4), 398-406. https://doi.org/10.1207/s15327752jpa4504_9

Levy, M. \& Gumpel, T. P. (2020). Self-efficacy and external locus of control as predictors of participant roles in relational aggression. Journal of Interpersonal Violence, O0(0), 1-26. doi:10.1177/0886260520943733

Linley, P. A., Joseph, S., Harrington, S., \& Wood, A. M. (2006). Positive psychology: Past, present, and (possible) future. The Journal of Positive Psychology, 1(1), 3-16. doi: 10.1.1.334.7970

Lyubomirsky, S., King, L., \& Diener, E. (2005). The benefits of frequent positive affect: Does happiness lead to success? Psychological Bulletin, 131(6), 803-855.

Maddi, S. R. \& Khoshaba, D. M. (1994). Hardiness and mental health. Journal of Personality Assessment, 63(2), 265-274. doi: 10.1207/s15327752jpa6302_6

Nowack, K., \& Niemirowski, A. (2021). Cognitive hardiness in coaching: Personality trait, skill, or outcome? Coaching Psychologist, 17(1), 14-31. https://searchworks-lb.stanford.edu/articles/aph__150353159

Periasamy, S. \& Ashby, J. S. (2002). Multidimensional perfectionism and locus of control. Journal of College Student Psychotherapy, 17(2), 75-86. doi: 10.1300/J035v17n02_06

Poudel, A., Gurung, B., \& Khanal, G. P. (2020). Perceived social support and psychological wellbeing among Nepalese adolescents: The mediating role of self-esteem. BMC Psychology, 8(43). https://doi.org/10.1186/s40359-020-00409-1

Pressman, S. D. \& Cohen, S. (2005). Does positive affect influence health? Psychological Bulletin, 131(6), 925-971. https://doi.org/10.1037/0033-2909.131.6.925

Qualtrics. (2020). Qualtrics (June, 2021) [Computer Program]. Provo, Utah. https://www.qualtrics.com/

Rotter, J. B. (1954). Social learning and clinical psychology. Prentice-Hall, Inc. https://psycnet.apa.org/record/2005-06617-000?doi=1

Rotter, J. B. (1966). Generalized expectancies for internal versus external control of reinforcement. Psychological Monographs: General and Applied, 80(1), 1-28. https://doi.org/10.1037/h0092976

Ryff, C. D. (1989). Happiness is everything, or is it? Explorations on the meaning of psychological well being. Journal of Personality and Social Psychology, 57(6), 1069-1081. https://doi.org/10.1037/0022-3514.57.6.1069

Skomorovsky, A. \& Wan, C. (2019). The impact of financial strain and external locus of control on psychological distress among single CAF members with children. Journal of Military, Veteran and Family Health, 5(1), 71-81. doi:10.3138/jmvfh.5.s1.2018-0028

Sona, A., Bhalla, A., \& Kaur, B., (2020). To study the predictors of happiness on locus of control and gratitude among adolescents. Indian Journal of Positive Psychology, 11(4), 398-401. https://iahrw.org/our-services/journals/indian-journal-of-positive-psychology/

Stevenson, J. C., Millings, A., \& Emerson, L. (2019). Psychological well-being and coping: The predictive value of adult attachment, dispositional mindfulness, and emotion regulation. Mindfulness, 10, 256-271. https://doi.org/10.1007/s12671-018-0970-8

Strong, S. L., \& Gore, J. S. (2020). The mediating role of locus of control between social resource stability and psychological well-being. Journal of Applied Social Psychology, 50(8), 464-475. https://doi.org/10.1111/jasp.12674

Veenhoven, R. (2008). Sociological theories of subjective well-being. In: M Eid, RJ Larsen (eds). The science of subjective well-being. Guilford Press.

Walsh, J. J., Wilding, J. M., Eysenck, M. W., \& Valentine, J. D. (1997). Neuroticism, locus of control, type A behaviour pattern and occupational stress, Work and Stress, 11(2), 148-159, doi:10.1080/02678379708256831

Xia, T. \& Ma, Z. (2020). Social integration, perceived stress, locus of control, and psychological wellbeing among chinese emerging adult migrants: A conditional process analysis. Journal of Affective Disorders, 267, 9-16. https://doi.org/10.1016/j.jad.2020.02.016

Publish your research article in AIJR journals-

$\checkmark \quad$ Online Submission and Tracking

$\checkmark$ Peer-Reviewed

$\checkmark$ Rapid decision

$\checkmark \quad$ Immediate Publication after acceptance

$\checkmark \quad$ Articles freely available online

$\checkmark \quad$ Retain full copyright of your article.

Submit your article at journals.aijr.org
Publish your books with AIJR publisher-

$\checkmark \quad$ Publish with ISBN and DOI.

$\checkmark \quad$ Publish Thesis/Dissertation as Monograph.

$\checkmark \quad$ Publish Book Monograph.

$\checkmark \quad$ Publish Edited Volume/ Book.

$\checkmark \quad$ Publish Conference Proceedings Retain full copyright of your books.

Submit your manuscript at books.aijr.org 